\title{
Learning Experiences of Nursing Students in Online RN-BSN
}

\section{Programs in the United States}

\author{
Elaine Della Vecchia ${ }^{1 *}$ \\ ${ }^{1}$ New York Institute of Technology (Assistant Professor, Department of Nursing), Old Westbury, New \\ York, United States \\ *Elaine Della Vecchia, E-mail: edellave@nyit.edu
}

Received: August 15, 2017

Accepted: August 22, 2017 Online Published: August 28, 2017

doi:10.22158/rhs.v2n3p291

URL: http://dx.doi.org/10.22158/rhs.v2n3p291

\begin{abstract}
The complex profession of nursing requires the practitioner to be knowledgeable, skilled, and autonomous. It is estimated in the USA 36.8 percent of nurses hold degrees at the baccalaureate level and above. Evidence indicating baccalaureate-degreed nurses are better prepared to meet the demands of this complex profession has led to policymakers and practice leaders touting the importance of this degree. RNs are seeking the BSN degree in increasing numbers. However, due to family, work, and personal time constraints, traditional means of education may not be a viable option for many, and distance learning provides an alternative for students who might not be able to pursue degrees. The number of RN-BSN online education programs has increased significantly over the last decade. There is a great deal of research regarding the efficacy of these programs but little research exists regarding the learning experiences $R N-B S N$ students have in these programs. The intent of this research study was to examine the structure of the learning experiences of RN-BSN students participating in online education programs. To accomplish this goal, data were obtained from 11 interviews with RN-BSN online education students about their perceptions and assumptions before beginning their coursework, and their perceptions and actual experiences, as well as, perceived challenges after experiencing the programs.
\end{abstract}

\section{Keywords}

Online education, $R N-B S N$ programs, learning experiences

\section{Introduction}

Nursing is the USA's largest health care profession, with more than 3.1 million registered nurses nationwide (Health Resources and Services Administration, 2010). Quality patient care, low mortality rates, and decreased medication errors requires the nurse to be knowledgeable, skilled, and competent. The expanded scope and intricacy of nursing practice demands a workforce that is more than adequately 
prepared. Quality outcomes have been linked to nurses prepared at the baccalaureate and higher degree level.

It is estimated in the USA, only 36.8 percent of today's nurses hold degrees at the baccalaureate level and above (American Association of the Colleges of Nursing (AACN), 2011). Based on this data, The National Advisory Council on Nurse Education and Practice (2010) has urged that at least two thirds of the nursing workforce hold baccalaureate or higher degrees in nursing. The American Organization of Nurse Executives has recommended a nationwide effort to substantially expand the availability of baccalaureate nursing programs, citing a growing body of research supporting the relationship between the levels of nursing education and both the quality and safety of patient care (American Organization of Nurse Executives (AONE), 2015). Other researchers have suggested that not only is the baccalaureate degree essential to properly prepare nurses, but that it may also be essential to stabilize the nursing workforce. Studies indicate baccalaureate-prepared nurses were found to have higher levels of job satisfaction, which is key to nurse retention and, in turn, vital to ensuring high-quality health care.

The chorus of recommendations for advanced nursing education has led to an increase in opportunities available for nurses to continue their education. Often nurses who are being encouraged to pursue a baccalaureate degree are not doing so because of family, work, and personal time constraints. Obtaining a baccalaureate degree through traditional means of education is, for many nurses, simply not a viable option. Varying work schedules may make participation in traditional education programs difficult, if not impossible. As a result, the need for online RN-BSN programs have intensified. These online RN-BSN programs has become a viable and often preferable educational option for nurses who seek higher degrees. Online education can provide learning experiences for many who, for whatever reasons, may not pursue similar opportunities in a traditional setting. Online education has eliminated many of the obstacles faced by today's busy students, providing increased availability to learning opportunities by accommodating the lifestyles of many individuals who otherwise would not be able to attend college. Currently the USA has $747 \mathrm{RN}$ to BSN programs available nationwide, including more than 600 programs that are offered at least partially online. Program length varies between 1 to 2 years depending upon the school's requirements, program type and the student's previous academic achievement (AACN, 2017).

The growth in popularity of online education has sparked numerous research studies on the efficacy these programs. Less prevalent in the literature are studies that involve the learners' educational experiences in these programs.

A growing consensus among nursing leadership points to evidence indicating that the baccalaureate education provides a better foundation for preparing nurses to meet the demands of a rapidly changing health care system. As a result, nursing leadership advocates baccalaureate education to adequately prepare nurses for their complex roles.

The profession needs individuals capable of thinking critically and solving problems cleverly, along with a sound foundation in a broad range of basic sciences. Nurses must possess knowledge of 
behavioral, social, and management sciences, as well as the ability to analyze and communicate data.

Registered nurses work on interdisciplinary teams with colleagues educated at the level of master's degree or higher. Other health care professions recognize the intricacies involved in providing patient care and understand the value and need for higher education. Because nurses are primarily responsible for providing and coordinating direct patient care, it would only stand to reason that these practitioners should not be the least educated member of the health care team.

Baccalaureate-degreed nurses play a vital role in the delivery of safe, comprehensive patient care. Research suggests hospitals employing higher proportions of baccalaureate-prepared nurses tended to have lower mortality rates. Additionally, surgical patients cared for in hospitals in which higher proportions of direct-care nurses held baccalaureate degrees experienced a substantial survival advantage over those treated in hospitals in which fewer staff nurses held baccalaureate or higher degrees. Similarly, surgical patients experiencing serious complications during hospitalization were significantly more likely to survive in hospitals with higher proportions of nurses who had completed a baccalaureate education.

As many health care institutions strive to achieve recognition for excellence of care, they encounter the problem of scarcity of a highly professional, well-educated nursing work force whose members can transform the process of patient care. The task of developing and employing upgraded care is made more difficult because nurses are unprepared to use evidence-based practice and research methods as a problem-solving tool to improve patient outcomes.

There are three major educational paths which can be followed to become a registered nurse in the USA: (a) a 3-year diploma degree from an accredited nursing program; (b) a 2-year associate's degree, typically available through community colleges; and (c) the 4-year baccalaureate degree offered by senior colleges or universities. Graduates of all three programs sit for the same licensing examination. Over the years, nursing has evolved into a complex and dynamic profession. The increased diversity and scope of practice requires nurses to be both knowledgeable and highly skilled. Because nurses are primary caregivers, their education must prepare them for this multifaceted role. To be successful, nurses' educational foundation should instill knowledge in a broad range of basic sciences (behavioral, social, and management), the capability to analyze and communicate data, and the competency to engage in critical thinking and problem solving. Among the three entry-level nursing education programs, only the baccalaureate program provides the opportunity for students to obtain in-depth instruction in the physical and social sciences, nursing research, public and community health, nursing management, and the humanities.

Growing evidence indicating baccalaureate-degreed nurses are better prepared to meet the demands of today's challenging nursing profession has led policy makers and practice leaders to recognize the importance of this degree. In 2003, the National Advisory Council of Nursing Education and Practice strongly proposed naming the baccalaureate preparation program as the preferred path for registered nurses to enter the health care system, thereby ensuring a work force that is competent to meet today's 
and tomorrow's complicated demands. In 2004, in response to this recommendation, Congress passed the Nurse Reinvestment Act (NRA), legislation that amends Title VIII of the Public Health Services Act to address the growing nursing shortage. Specifically, the NRA includes scholarship programs that provide support to individuals for nursing education with a payback provision following graduation.

In March 2005, the American Organization of Nurse Executives (AONE, 2005) released a statement indicating the baccalaureate degree is the only degree that adequately prepares nurses for the challenges of their complex roles. Then, in February 2007, the Council on Physician and Nurse Supply (CPNS, 2007) encouraged a national effort to substantially expand baccalaureate nursing programs. The council called on policy makers to shift federal funding priorities in favor of supporting more baccalaureate-level nursing programs.

The AACN (2008) revised its framework of nursing education to require new skills sets for baccalaureate-prepared nurses. These new skills sets were established as part of a plan to assist nurses to better meet the demands of the changing health care profession. Generalized as the required components of professional nursing education were liberal education, professional values, core knowledge, and role development. To effectively prepare nurses, the AACN indicated nine specific and essential elements for baccalaureate nursing education: (a) liberal education for baccalaureate generalist nursing practice; (b) basic organization and leadership skills for quality care and patient safety; (c) scholarship for evidence-based practice; (d) information management and patient care technology; (e) healthcare policy, finance, and regulatory awareness; (f) communication and collaboration for improvement of patient health outcomes; (g) clinical prevention and population health; (h) professionalism and professional values; and (i) baccalaureate generalist nursing practice. The AACN expected that both traditional and distance education programs would adjust their programs to be compliant with these new requirements. In October 2010, the Institute of Medicine released its landmark report on The Future of Nursing, which called for increasing the number of baccalaureate-prepared nurses in the workforce to $80 \%$ by 2020 . The expert committee charged with preparing the evidence-based recommendations in this report state that to respond, "to the demands of an evolving health care system and meet the changing needs of patients, nurses must achieve higher levels of education".

In September 2013, the Robert Wood Johnson Foundation released a newsletter which outlined how patients, employers, and the profession benefits when nurses advance their education. Articles focus on the evidence linking better outcomes to baccalaureate and higher degree nurses, educational pathways, and promising strategies for facilitating academic progression at the school, state, and national levels (AACN, 2015).

New York and New Jersey have been introduced by state nursing associations to require the baccalaureate degree for all registered nurses with 10 years of graduation from an entry-level RN program, the proposal is known as "BSN-in-10" proposal.

AACN's (2017) most current data indicates enrollment in RN-BSN programs is increasing in response to calls for a more highly educated nursing workforce. From 2015 to 2016, enrollments increased by 1.0 
percent, marking the 13th year of increases in RN to BSN programs. Both traditional and online RN-BSN programs are designed to develop clinical reasoning and analytic skills needed for nurses to advance their careers. The courses in these programs build on the fundamental knowledge obtained in the initial nursing education program. The education focuses on a wider scope of care delivery, examining issues such as cultural, political, economic, and social issues and the influence on patient care. The goal is to enhance professional development.

The need for online RN-BSN educational programs has increased dramatically, yet little research has been conducted regarding the learning experiences RN-BSN students have in these programs. Sit, Chung, Chow and Wong (2005) suggested students' satisfaction with distance education is influenced by their learning experience but found few studies had been conducted on those experiences. More importantly, scarce research has documented the effect these experiences might have on the attrition rate of students who participate in distance education programs.

The purpose of the study was to advance nursing education by gaining an understanding of the learning experiences students had in online RN-BSN programs. To date, little research has been conducted on the structure of the learning experience in RN-BSN online programs. This study sought to identify RN-BSN students' learning experiences, and to explore the effects of these experiences on the students' actual learning. Gaining insight into these students' learning experiences may assist in determining the positive and negative perceptions students have regarding this educational venue.

Enhancing students' learning experience is critical to the success of online education, regardless of the curriculum. Online learning provides a viable option for nurses who might not otherwise could continue their education. By tapping into this learning resource, more nurses will be able to advance their personal knowledge, as well as the nursing profession. Regardless of the academic program, if students' expectations of distance learning experiences are not congruent with the actual practice, the value of this venue can be compromised. To enhance the student's learning experience in online education programs, an understanding of the students' perspective on the learning experience is needed. The online learning nursing student's perspective has implications for nursing faculty and educational institutions alike. Faculty have a responsibility to foster positive learning experiences. Gaining insight into students' experiences in online RN-BSN programs can assist faculty to develop teaching methods that will equip the student to optimally manage this nontraditional scholarly venue.

This study sought to gain insight into the learning experiences of online RN-BSN nursing students, the following research question was addressed: "What is the structure of the learning experience for RNs who are enrolled in online RN-BSN programs?"

\section{Method}

A descriptive phenomenological research method was utilized for this study to explore the participants' lived experiences with online education. To accomplish this objective, Colaizzi's (1978) seven-step phenomenological analysis process was employed. 
Eleven participants were selected through network (snowball) sampling from those RNs who were currently enrolled in RN-BSN online education programs or who had completed the degree within the past 12 months. The number of participants was based on the range and scope of the interviews, which continued until data saturation was reached.

Of the participants, $91 \%$ were female and $9 \%$ were male. This was consistent with AACN (2015) data. Participants ranged in age from 32 to 56 years ( $M=48.4$ years). Ninety-one percent had graduated from RN-BSN programs within the past 12 months; $9 \%$ were currently enrolled in RN-BSN programs and had completed at least $50 \%$ of the required course work. Four USA universities were represented. All participants were Caucasian. Eight of the 11participants were married; 5 participants had children who lived at home. All participants were employed full-time: 2 worked in outpatient areas, 1 in nursing administration, and 8 in various units (medical/surgical, intensive care, and oncology) as staff nurses. All participants had computers at home. Participants represented five different states and three different regions of the United States: 2 from the Midwest, 1 from the South, and 8 from the Northeast. All spoke English.

Semi structured interviews to collect data were conducted via telephone at days and times of the participants' choice. The goal of the interviews was to elicit as many different stories and experiences, which included both depth and breadth of information, as possible. All participants received and signed informed consent forms prior to their participation in the study. A script was used to ensure that all eight interview questions were addressed. Interview times varied from 10 minutes to 2 hours ( $M=45$ minutes). The significance and quality of information also varied by participant. The conversations were audio recorded, with participants' consent, for subsequent verification and transcription purposes. The participants were asked to assist in the analytical stage by validating their experiences. A copy of their respective transcripts was sent to the respondents via e-mail; participants were asked to review the transcripts to ensure their experiences had been captured truly and accurately. The participants were instructed to add any further comments as well.

Data collection occurred at locations chosen by the individual participants. The settings needed to be quiet and private. The times at which the interviews occurred were also the participants' choice. Enough time was needed to describe their experiences efficiently but completely.

\subsection{Bracketing}

To address bracketing in this study, the researcher kept a journal of field notes made before, during, and immediately following each interview. These notes assisted the researcher in preparing for the interview process. The notes contained descriptions of the researcher's thoughts and feeling about each interview and assisted in providing in-depth data related to the interview process. This was done to become more cognitive of potential biases.

\subsubsection{Protection of the Participants}

To protect anonymity of the participants, coded numbers were utilized to identify the participants during the research process and publications. Because the study involved the use of audiorecordings, to maintain 
the participants' right to privacy, all audiorecordings, list of coded names, and transcriptions will be kept in a locked cabinet and will be erased or shredded, as appropriate to the medium, 5 years after the completion of the study. During the interviews, confidentiality of the participants was maintained by not identifying them by name. Data was recorded utilizing fictitious names in order to ensure there was no association between the coded name and the participant's identity. The tapes and transcripts do not contain any information that could connect data to a specific participant. List of coded names were kept separate from the verbatim transcripts and are available only to the researcher.

\section{Result}

The study employed a 7-step phenomenological analysis process, as described by Colaizzi (1978). NVivo ${ }^{\circledR} 8$ software, designed to store, organize, and represent qualitative data, was used to aid in the analysis process. Colaizzi's phenomenological analysis process includes a review of all the protocols and extraction of significant statements, elucidation of the meaning of each significant statement; organization of significant statements/meanings into clusters of themes with notations of discrepancies among themes, integration of results into exhaustive descriptions of the phenomenon, preparation of a statement of identification of the phenomenon, and participant validation of the findings.

Coding generated 66 key invariant constituents, which were clustered into six themes that represented the experiences and perceptions of the student participants about RN-BSN online education programs (Table $1)$.

Table 1. Theme Clusters and Invariant Constituent Distribution for Interviews

\begin{tabular}{lc}
\hline Theme clusters & \# of invariant constituents \\
\hline Assumptions/preconceptions & 7 \\
Actual program experience & 18 \\
Comparisons between online and traditional settings & 9 \\
Advantages to online programs & 6 \\
Disadvantages to online programs & 20 \\
Satisfaction with program & 6 \\
\hline
\end{tabular}

The first theme cluster, assumptions and preconceptions, encompassed any assumptions, expectations, or preconceived notions participants had prior to participation in the program. This first cluster was determined by seven invariant constituents. The invariant constituents central to this theme include the following: (a) none/not sure what to expect (5 of 11 participants); (b) low expectations ( 2 of 11 participants); (c) nervous/dreaded the computer aspect of the program (2 of 11 participants); and (d) expected it to be like going to traditional class/like it was for their associate's degree ( 2 of 11 participants). 
Three invariant constituents were noted by a single participant each. These included the thought that it would be easier than it was, the thought that it would be more difficult than it actually was, and the expectation to self-teach. The invariant constituents representing the variety of participant responses are presented in Table 2. The primary element in terms of preprogram participation assumptions appears to be that the students did not know what to expect, creating a void of assumption or preconceived notions.

Table 2. Assumptions/Preconceptions

Invariant constituents \# of participants to offer this experience $(\mathrm{N}=11)$

None/not sure what to expect 5

Low expectations 2

Nervous/dreaded computer aspect 2

Expected would be like traditional classes/associates degree classes 2

Thought would be easier than was

Thought would be more difficult

Expected to self-teach

1

\subsection{First Theme Cluster}

Nearly one half of the study's participants noted that they had no assumptions or preconceived notions going into the program. Participant 2 expressed this absence of assumptions or preconceived notions as follows:

So, I knew that I couldn't go into a formal program and complete it. So, through word of mouth, I had heard of this but really didn't know what to expect, I wasn't quite sure how-I knew they were going to give me a textbook, I knew that there was going to be assignments, but I didn't quite know how it was going to be. I learned to be very self-guided through it but I really didn't—so it didn't meet or not meet expectations because I really didn't have any.

In a similar response, Participant 2 stated, "I had no idea what I was getting into. I was not enjoying my ground program, and I-actually, it was a very welcome change". Participant 6 mentioned, "I had no expectations. I really was a little clueless about how it was going to work".

Two students remarked that they held low expectations for the program, while 2 participants also noted they expected distance learning to be like attending traditional classes, as they had done when they obtained their associate's degrees. Participant 3 noted, "I didn't have very high expectations of what I would learn, to be honest. I thought that it would be very basic; just enough to meet the requirements". Participant 11 expressed her low expectations and how the program was not what she expected, stating, 
I assumed that with an online experience it was going to be a series of check boxes and yes or no questions. But it isn't. They are thought-provoking assignments. They are-it's very real-world based. It's very - it's labor intensive. You really should dig in and get into what you're doing to get through your class. They are short and sweet classes but, boy, you earn your money when you're doing it, let me tell you. They make sure that you come out of that class with a really solid understanding of the processes that they're trying to teach you.

This same participant expressed that she thought it would be just like getting her associate's degree: "So I went in with the expectation that it was going to be just a longer associate's degree sort of thing". Participant 1 remarked on her notion that distance learning would be the same as going to a traditional class: "I assumed it would be just like going to a class".

Two students expressed being nervous or dreading the computer aspect of the distance education, citing questionable confidence in their computer literacy as the cause for this anxiety. Participant 4 stated, "I was a little nervous with the whole computer part. I was fairly computer proficient, but, you know, would I be able to manage the work? You know, how computer literate does you have to be?" Participant 8 noted that, although she anticipated the technology aspect would be an obstacle, the program was very supportive and helpful in that regard. She stated,

But the first week or two, because I wasn't as computer savvy as I would have liked to have been when I started the program, I anticipated that being a very big problem and an obstacle, but they have all of those tutorials that help[ed] me through that. And whatever I couldn't get on a tutorial, I could make a phone call and get help from one of the people from the [university]. So, I anticipated it being more difficult in that respect.

The second theme cluster, actual program experience, consisted of 18 invariant constituents. The central invariant constituents to this theme included (a) learned from peers, as well as professors (6 of 11 participants, 55\%); (b) structured with clear expectations and objectives (5 of 11 participants, 45\%); (c) participation in group projects (5 of 11 participants, 35\%); (d) user-friendly system (4 of 11 participants, $36 \%$ ); (e) self-directed/guided (4 of 11 participants, 36\%); (f) program had computer tutorials (3 of 11 participants, 27\%); (g) shorter/more intensive program (3 of 11 participants, 27\%); (h) support from peers and professors ( 3 of 11 participants, 27\%); and (i) overwhelmed or frustrated at first (3 of 11 participants, 27\%). The level of learning from peers, as well as professors was significant, with $55 \%$ of respondents noting this constituent. Also significant were the number of students who felt the program was well structured with clear expectations. The invariant constituents and frequencies are identified in Table 3. 
Table 3. Actual Program Experience

Invariant constituents

\# of participants to offer this experience $(\mathrm{N}=11)$

Learned from peers, as well as professors

Structured with clear expectations

Group projects

User-friendly system

Self-directed/guided

Computer tutorials

Shorter/more intensive

Great support from peers and faculty

Overwhelmed/frustrated at first

Surpassed expectations

Orientation would have helped

Physical assessment done using observation/visitation/clinical

Physical assessment done using computer

Labor intensive

Real-world program

Optional lectures

Not easy, but convenient

Handicap service

Most students noted that they learned from their peers, as well as from their professors. Participant 3 stated, "I found that I learned as much from my peers and other professionals as I did from my facilitators". Participant 4 noted, "So you're mixing with people with all different backgrounds. You know, it might be business majors there, you know, whatever they might be, and, you know, so everyone's bringing to the table different experiences". Participant 9 agreed and stated, "I also liked the diversity that it brought dealing with people outside of my region". Likewise, Participant 5 touched on learning from the diversity of peers by stating,

Well, it was great because you really get to mingle and get to know people from all over the world, and how they perceive nursing, and how they perceive helping people. I found that, you know, quite interesting. And I also found it sometimes quite disturbing, you know, their perception of what work is, or how they would take care of a problem. You know, you're in your own little bubble, so to speak...

And I had girls that were like - they were doing home care in rural areas. I never even like really-I mean, I know it exists, but I never really put any thought into it. But listening to them, I was very impressed by those girls, I've got to tell you.

Participant 4 also touched on the aspect of structure, "It's actually very, very structured. We do the 
classes in 8-week sessions. Before this class even starts, we're able to open up that first week, just to get an idea of what the course content is". Participant 11 agreed with this sentiment, stating, "It was a very well-structured program". Similarly, Participant 5 noted,

It was structured - and I was pretty amazed because I went in and I never took a course online, so the first few courses, to me, were a little tough because, getting around, I found it difficult. I wasn't sure exactly what I was doing at first, so that took more time and more stress, I think, than the actual course itself, [which] was easy.

Some student participants commented on the inclusion of group projects in the program. Participant 6 noted,

I don't really know if the learning group was as successful as it could have been. Learning groups online is a little different. I think a lot of times, some individuals were doing more work than others, so sometimes people could kind of skate by.

Participant 8 described the positives and negatives of this aspect of the program:

It was structured where you were part of a team. There's pros and cons to being in a team but I thought it was a great learning experience because you need to learn how to work with people from all over the world that obviously we didn't have face-to-face interactions with, but you had their phone numbers if you needed to touch base with them. And you really needed to learn how to hold people accountable with deadlines and meet your own deadlines so that you could work together as team and conflict resolution. There were some team members that wanted to be team leaders and overpower the rest of the group. And for me, I just did my part and expected that kind of behavior from them.

Respondents commented on the need to be self-directed, while also noting the ease and user-friendly nature of the programs. Participant 4 stated, "The way that they have the courses set up, it's so easy to navigate around it". She gave a specific example:

We have this guy and he gives us a lecture on a Sunday night. And your chat thing is enabled that you can talk back to him if you wanted to. And he, right away, you go onto his desktop, and he does the entire- he's teaching us Excel and how to put in, you know, doing these graphs and things like that. He couldn't make it any more user-friendly than what he does with it.

Participant 9 commented on the learning platform, stating, "These were very user friendly". Participant 6 noted the need to be self-directed in the learning process and perhaps to be more focused than in a traditional setting. She stated,

It's just perhaps the way that I went about learning that material may have been a little different than the traditional classroom. I think you have to be a more focused individual because you really have to want to learn and want to do a little bit more than you may in a traditional classroom.

Participant 4 reiterated a similar sentiment and added, "It's self-directed, you know, like I'm doing two courses at a time, you can do one course at a time". 
The third theme cluster, comparisons between online and traditional settings, was determined by 9 invariant constituents. This category dealt with the students' perceptions of differences between the two learning environments. Most students (63\%) felt that the online program offered an equal level of education (36\%) or greater level of education (27\%) as compared to a traditional classroom setting. Participant comments within this category indicated online programs are geared more toward the adult learner (18\%), the online experience was better than the traditional setting (18\%), and that there is more equal participation (that discussion was not dominated by a few students, as in traditional settings/no "hiding") (18\%). All other invariant constituents were mentioned by only 1 participant, but included traditional classroom instruction has stronger clinicals, online professors are more supportive and available, traditional students are spoon-fed versus online students do their own research, and online students need to be more focused/self-learners. Responses categorized within this theme are presented in Table 4

Table 4. Comparison between Online and Traditional Settings

\begin{tabular}{lc}
\hline Invariant constituents & \# of participants to offer this experience (N=11) \\
\hline Same amount of education/equal & 4 \\
Better education/harder than traditional & 3 \\
Experience was better than traditional & 2 \\
Everyone participates/discussion not dominated by a few & 2 \\
Online more geared to adult learner & 2 \\
Traditional has better clinical system & 1 \\
Online professors more available/supportive & 1 \\
Spoon-fed vs. self-researcher & 1 \\
Have to be more focused online/self-learner & 1 \\
\hline
\end{tabular}

Many of the study's participants commented that they believed the level of education was at least equal to that of traditional environments, if not better. For example, Participant 5 stated,

I think the focus is the same. I think the requirements are essentially the same. You're asked to do the same types of things. It's just perhaps the way that I went about learning that material may have been a little different than the traditional classroom.

Participant 10's response paralleled this sentiment, reporting, "What I feel like is really I got the same amount of education as what anyone in a traditional program would but I just got it in a different way". Participant 11 echoed this opinion, stating,

I think it's equitable. I think that it's very-it's equal. I don't feel any less able to-less educated than they even though we're at the same level ... I feel my education is up to par with anybody. I will match it side by side with anybody. 
Participant 9 asserted that distance learning was better than the traditional venue, commenting,

I think it was better. I think there was more expected of me, and I had to put more effort into it by writing the papers every week and applying what we learned and doing the interactive discussion questions. The material is not handed to the student, every week there is a fair amount of time reading and researching the topic being focused on. Through the research process, reading articles and books, along with writing papers the material is reinforced weekly, not just memorized or discussed once in a semester, only to be later forgotten.

Participant 1 remarked similarly, stating, "I think it's better because this is something I wanted and to get what I wanted, I had to work hard".

Some respondents suggested that the online environment may be more geared to the adult learner. Participant 9, for example, stated, "I did find it was more geared to the adult learner", while Participant 11 stated, "The expectation is that you are a grown-up that has real-world experience and ... [the program] gives you this vast resource of knowledge". All other invariant constituents received only one mention by participants.

The fourth theme cluster, advantages to online programs, was determined by 6 invariant constituents. The overwhelming majority of students cited the flexibility of the online/distance education format as an advantage in terms of the ability to access and participate in the program on their own time and from any location (10 of 11 participants, 91\%). Six of 11 participants (55\%) mentioned the advantage of having diverse classmates with different insights and experiences to learn from. The invariant constituents and the frequencies among participants relative to this theme cluster are presented in Table 5.

Table 5. Advantages to Online Programs

\begin{tabular}{lc}
\hline Invariant constituents & \# of participants to offer this experience $(\mathrm{N}=11)$ \\
\hline Flexibility/own time and place & 10 \\
Diversity of classmates to learn from & 6 \\
Doesn't take time away from family & 2 \\
Clear expectations & 2 \\
6-week course versus 12-week course & 2 \\
Able to replay lectures/review discussions & 1 \\
\hline
\end{tabular}

Most respondents remarked on the advantage of flexibility of the online/distance education model. Participant 1 stated,

You could do it on your own time, you know, when you're in class, you had to be at school a certain date, a certain time, and you were locked in to that date and time. When you're online, you could get home late from work and start working at it at midnight, if that's what you prefer to do. I found the convenience was very good. 
Participant 2 reported similar sentiments, noting,

Well, in my case it was the flexibility of learning time because I didn't have the luxury of signing up for formal classes on given days. So that was the first advantage for me. The second advantage was that I could sit down and read when I found the time to sit down and read, or sit down and do my assignments when I found time so it wasn't—as long as I was completed [with] whatever was needed to be done by the end of the week, I was in good shape. It wasn't that you're in class on Tuesday; this paper has to be in on Tuesday. It was this has to be done in a 7-day period, make your time to do it, which worked very well for me. Also, as I said to you earlier, we had people all over the country, so I'm talking to people in California and so if, say, I'm someone who's up at 2 o'clock in the morning, I probably am still talking to some of my fellow students, maybe up at 9, 11 o'clock at night. So that was a nice advantage to the program also.

Participant 6's responses were like those expressed by Participant 2:

The biggest advantage is that you're able to-I'm not tied down to going to a facility at a specific time for a specific amount of time. That was the biggest advantage for me, to be able to sit down and go to class whenever I could fit it into my schedule. As a working mom, that really was the biggest advantage for me.

Participant 8 remarked on the elements of time and location flexibility:

Time is a big factor, especially for somebody who's working full-time. You know what you must do but you can fit it into your lifestyle better. You can learn at your own pace, so to speak. Yes, you should learn everything within a certain time-period, but you know what's due and you can take your own time to do it within that 5 weeks. You can go on vacation. You can go all over the place. I've gone to islands and found little Internet cafes and continue to go to school so it really didn't disrupt my lifestyle at all.

Participant 7 agreed, stating, "But to me personally, the best advantage was not having to physically go somewhere at a specific time, doing it on my terms; that was the one thing that was definitely done on my terms".

Many students remarked on the advantage of the diversity of their classmates and the interaction with these classmates. Participant 9 noted the enhancement of the program because of this diversity, stating,

I think I ended up with a better experience because of the diversity and everybody being from different areas. I wasn't being influenced by one instructor or a certain group of classmates. Assumptions were not made about me based on where 1 lived or where I worked.

Participant 2's response was similar:

Even just getting other peoples' insights ... and I think you didn't—-the interaction with people in other parts of the country, you know, especially with health care, health care is very different in, let's say, in New York than it is in California. In some respects, and I think that's such a great learning experience. 
Participant 1 echoed this aspect of distance learning, stating,

I'm writing to other students from all over the country that have been working with this ... the pitfalls, the advantages, the different systems they've used, what they found was different about this compared to that. I think it's a great learning experience.

The fifth theme cluster, disadvantages to online programs, consisted of 20 invariant constituents. This category represented the factors that students perceived as disadvantages to the program. The primary invariant constituents in this category included (a) no face-to-face contact (5 of 11 participants, 45\%); (b) weakness of group projects (5 of 11 participants, 45\%); (c) some level of social isolation (3 of 11 participants, 27\%); (d) difficult to make connections/not as connected to facilitators (2 of 11 participants, $18 \%$ ); (e) computer crashes/shutdowns (2 of 11 participants, 18\%); and (f) specifically, math (statistics) was difficult in an online format ( 2 of 11, 18\%). Other invariant constituents were noted, but received only a single mention by respondents. These included (a) self-learning would be difficult for younger and less experienced individuals; (b) more difficult; (c) must be self-directed; (d) intensive; (e) timed tests; (f) self-arrangement of clinicals; (g) more expensive; (h) too much time on computer; (h) no disadvantages; (i) physical assessment difficult online; (j) impersonal; (k) delays in responses; and (l) difficult to understand the emotions behind discussions. Frequencies and primary invariant constituents are presented in Table 6.

Table 6. Disadvantages to Online Programs

Invariant constituents $\quad$ experience $(\mathrm{N}=11)$

\# of participants to offer this experience $(\mathrm{N}=11)$

No face-to-face contact

5

Weakness of group projects 5

Some level of social isolation 3

Difficult to make connections/not as connected to facilitators 2

Computer crashes/shutdowns 2

Math (statistics) difficult online

To illustrate the most common responses within this cluster of themes, Participant 5 noted the lack of face-to-face contact as a disadvantage, stating,

I guess the face-to-face contact with people, you know, making a long-distance relationship as opposed to you might be able to make a more intimate relationship with somebody. I mean, I still have friends that I went to nursing school with, that I still see all the time. You know, the instructors, too, you don't really have that one-to-one with your instructor. You know, if you do come across a problem or something, it's a little—it's impersonal. 
Participant 6 reiterated the sentiments expressed by Participant 5, stating,

One of the disadvantages is not having face-to-face conversations with either other students or the professor. I did find it a little difficult to make connections and I do find that, you know, sometimes the connections you make when you're in school are long-lasting or also you get to connect outside of the classroom environment. With online learning, that doesn't really happen.

Participant 9's comments echoed this element, stating,

Sometimes it would be nice to be able, if you're having a problem with the instructor, to see them face to face. It can be frustrating to communicate differences or ask questions without being able to see the person on the other end. It can be difficult to understand the emotions behind some of the discussions, and you have to base them how one responds to questions.

Many participants reported on the weakness of the group project format. For example, Participant 5 stated,

The biggest obstacle, I found, was the group projects ... I would be up on a Sunday night until 4 in the morning, having to go to work the next day, doing somebody else's work, to hand in a project because a lot of the professors, I found, never checked who did what, who-you know. And then you'd have somebody promising you the world and you'd never get the material delivered.

Participant 6 commented on the weaknesses of group projects and the difficulties with this format in an online environment, stating,

I don't really know if the learning group was as successful as it could have been. Learning groups online [are] a little different. I think a lot of times some individuals were doing more work than others, so sometimes people could kind of skate by ... I think the purpose of the learning group is to really help people learn how to work with others or to do team-building type of stuff and I don't think that really was successful in that regard.

Participant 11 offered this insight into the group project experience:

Another disadvantage is that, and I ran across this time and time again, some of the learning groups that we would be with. There would be - there was always this random person that couldn't spell, didn't know grammar, and would really drag the group down, and they give us a group grade no matter how many times, you know, I know there was several classes that I brought it to the attention of the facilitator. "Hey, look it, this lady can't put a sentence together in the correct order". And I tried everything I know. But our grade's going to be impacted because she says, "I been done that", and it's reflected in her work. And as the editor, we're having to do all her work. Why-it can't continue. So - and it was just never addressed and that sometimes-sometimes I would almost get the sense like, no matter what you do, you're going to get the same grade.

Participant 11 commented on changes in the way that the group projects are evaluated, suggesting,

And I think that that's the one thing that I would change (that) as far as the group learning is concerned, is that, yes, the group grade is important, but I really do think you need to look at individual contributions as well. 
Within this cluster of themes, the final significant theme that emerged from the interview process was that some level of social isolation served as a disadvantage to the program. Participant 2 commented, "On the online, you have a support system, but it's not always the same. There is some social isolation, I think". Participant 7 and Participant 8 concurred with the interviewer's comment on social isolation.

The sixth and last theme cluster, satisfaction with the program, was determined by 6 invariant constituents. These invariant constituents reveal the experiences of participants that represent the level of satisfaction, relevance to their practice, and desire to further continue in an online/distance education format. All 11 participants expressed overall satisfaction with the learning experience. The specific invariant constituents for this thematic category included (a) satisfied with overall learning experience (4 of 11 participants, 36\%); (b) very satisfied with the learning experience (5 of 11 participants, $45 \%$ ); (c) extremely satisfied with the learning experience ( 2 of 11 participants, $18 \%$ ); (d) continuing to obtain a master's degree online (7 of 11 participants, $64 \%$ ); and (e) relevance to practice ( 8 of 11 participants, 73\%). The invariant constituents and their frequencies are presented in Table 7.

Table 7. Satisfaction with the Program

\begin{tabular}{lc}
\hline Invariant constituents & \# of participants to offer this experience $(\mathrm{N}=11)$ \\
\hline Overall satisfaction with learning experience & 11 \\
Very satisfied & 5 \\
Satisfied & 4 \\
Extremely satisfied & 2 \\
Relevant to practice & 8 \\
Continuing on with master's online & 7 \\
\hline
\end{tabular}

The key invariant constituents of satisfaction with the program revealed a high degree of overall satisfaction with the online format, with $100 \%$ expressing overall satisfaction. This satisfaction was evident with $64 \%$ of the participants planning to continue to further their education to the master's level using the same learning format. Exemplifying the invariant constituent of continuing to the master's level online, Participant 2 stated,

I was satisfied. My goal was to get my BSN. I got it ... It happened. I did learn. And I guess the best testament to that would be me saying to you that I feel that I will enroll ... after I do some more research, in a master's program.

Participant 3 expressed interest in continuing with an online format for a master's program, stating,

Extremely [satisfied]. I went on to do a dual master's degree as well. I chose this format intentionally, because I felt that it would better prepare me for formal writing — better preparing [sic] me for publication. I also have encouraged many of peers who require a BSN to do the ... RN-BSN program. It was such a great foundation for my professional practice. 
Participant 11 expressed similar feelings, stating, "I'm just very satisfied. I mean I think it's obvious. I can speak in glowing terms of the whole program and I'm looking forward to starting my master's there".

Most respondents (73\%) believed the learning experience related to their current practice. Participant 2 noted, "Yes, I think-yes, it was pertinent to my practice, because I felt that it made me grow as a nurse". Participant 3 responded positively when asked if the program was relevant to her practice, stating,

Very much so, because the program focused on application of the concepts. It was a great way to be immediately able to apply what we were learning, and was immediately useful. This was one of the best features of the program, I think. We didn't just learn concepts-there were real-world applications.

Participant 4 reiterated this sentiment, stating,

In fact, part of what you are doing within the courses, it's required, every course that I've done thus far, they tie it back into what you're - or they attempt to tie it back in or they want you to try and take the experiences that you're do- that you have, tie them into what you're learning. And then they want you to take what you've learned new and say how you're going to take it back into your daily practice.

Participant 11 added insight into the critical elements of the question of relevance to practice, stating, When you're doing the RN to the BSN, the bridge to the bachelor's, it really is based on theory. The theory which provides you - and it was a wonderful experience because it provided an avenue of thought that I had not considered before and it really helped to shape my practice to be much, much better.

\section{Discussion}

\subsection{Assumptions/Preconceptions}

From the cluster of themes presented, the data suggest that the majority (45\%) of RN-BSN online education/online nursing students entered the program not knowing what to expect. Some (36\%) began the program nervous about the technology involved or with generally low expectations. What these students experienced is a program that is very much self-guided but well structured, with clear expectations set for each student, supportive in terms of technology and personal availability, and user friendly with convenient and flexible access to coursework and requirements. The participants in this study described a dynamic learning experience that is unique in that it builds knowledge not only from academic study but also from the vast experiences and insights of a diverse and interactive peer group. The level of education earned was believed by participants to be equal to or greater than that received from a traditional classroom setting, though the self-directed format may be better suited or geared to adult learners. 


\subsection{Actual Program Experience}

The second theme cluster, actual program experience, consisted of 18 invariant constituents. The participants recounted the varied experiences they had regarding the program. The majority (55\%) of students stated that they learned from their peers, as well as from their professors and facilitators. The central theme also included structure with clear expectations and objectives, participation in group projects, user-friendly system, self-directed/guided, program had computer tutorials, shorter/more intensive program, support from peers and professors, overwhelmed or frustrated at first.

\subsection{Comparisons between Online and Traditional Settings}

The third theme cluster focused on comparisons between online and traditional settings, consisting of nine invariant constituents. This category encompassed the students' perceptions of differences between the two learning environments. The majority (63\%) of students felt that the online program offered an equal level of education (36\%) or greater level of education (27\%) as compared to a traditional classroom setting. Participant comments within this category indicated online programs are geared more toward the adult learner, or the online experience was better than the traditional setting, and that there is more equal participation (that discussion was not dominated by a few students, as in traditional settings/no "hiding"). The participants stated that traditional classroom instruction has stronger clinical guidance, whereas online professors are more supportive and available.

\subsection{Advantages to Online Programs}

The advantage of an online learning environment is flexibility; this was a consistent theme echoed by 10 of the 11 participants (91\%). Flexibility is a major draw for the program. Where it may otherwise be impossible for nurses to attend an advanced education program due to schedule demands of work, family, and location, the online learning environment offers an opportunity. Unorthodox and inconsistent work hours for many nurses (e.g., those on the night shift or who work rotating shifts) make attending a traditional setting impossible or, at best, inconvenient. Nurses in rural locations may have no access to local classroom programs, and demands of family can reduce or eliminate available time opportunities for furthering education. Online learning environments remove these barriers by providing any time/any place availability for completion and participation in advanced studies, offering the opportunity for continuing education where none existed.

\subsection{Disadvantages to Online Programs}

The major disadvantages mentioned by participants included the lack of face-to-face contact (45\%) and the weakness of the group projects in the programs (45\%). Weaknesses in the group project format seem to be addressable and may be improved with implementation of strategies to identify individual contributions within group projects, as well as possible changes in grading procedures. The lack of face-to-face contact is inherent in the distance learning environment and many programs have made an effort to improve communications and offer options for communication utilizing new computer technology. This weakness may be mitigated further by more personalized contact on the part of the facilitators. Some respondents mentioned telephone interaction as an option within their programs, which 
may be a solution for those students who truly need more one-on-one, personalized contact. These disadvantages seem to pale in comparison to the overall advantages of the program, particularly in terms of accessibility, which contributed to the overall satisfaction of the participants.

\subsection{Satisfaction with Program}

Results of the study demonstrate overwhelming approval of these types of programs within the study sample, with a stated $100 \%$ satisfaction among participants. The degree of satisfaction is best illustrated by the high percentage (64\%) of respondents planning on beginning or already having begun their master's level studies utilizing the same online learning format. The participants expressed the sentiment that the instruction is relevant to their practice (73\%), which demonstrates their belief in the importance of the program's education in everyday nursing practice. They remarked positively when queried about how this education affected their practice for the better and should serve as a motivating factor.

Analysis of the data yielded valuable insight on the topic of preconceptions and perceptions of lived experiences of RN-BSN students who had completed all or at least $50 \%$ of an online education program. The information has important implications for theory, as well as future research. Implications are discussed in the following section.

Findings from this qualitative research study may be useful for expanding the body of knowledge regarding distance nursing education, particularly when compared with findings from past research in other fields. A growing consensus among nursing leadership supports the argument that the baccalaureate education provides a better foundation for preparing nurses to meet the demands of a rapidly changing health care system. In response to the profession's call to increase the availability of baccalaureate-degreed nurses, the number of RN-BSN programs has grown since the beginning of the 21 st century.

Nurses are being encouraged, both by their employers and nursing leaders, to return to school. Despite efforts to attract non-BSN RNs to acquire this higher level of education, the number of nurses returning to school has not increased dramatically. Online learning programs are very popular because the asynchronous format offers health care professionals the opportunity to attend classes at times convenient to their busy schedules. This study demonstrates overwhelming approval of these types of programs by the study sample.

From analysis of the interview statements, one theme "assumptions and preconceptions, encompassed any assumptions, expectations, or preconceived notions participants had prior to participation in the program" emerged. An important invariant constituent to this theme points to the concern that almost one half $(45 \%)$ of nursing students interviewed were not sure what to expect before starting the program and $18 \%$ of them expected it to be like going to traditional class. The findings in this study may assist distance education instructors and administrators in understanding and making decisions about the distance education program and course design.

The study might be used to develop strategies to improve the perceptions and learning experiences nursing students have regarding distance education programs. Such improvements might help to reduce 
the high attrition rates among distance learners and alter their perceptions regarding the learning experience. The study identified major disadvantages in distance education. Participants stated that the distance education experience' lack of face-to-face or in-person contact and the individual's contribution to group projects were not well identified.

Online learning has both strengths and weaknesses. The lack of face-to-face contact is inherent in the distance learning environment and many programs have tried to improve communications and optimize the use of new computer technology to mitigate this perceived shortcoming. This weakness might be mitigated further by more personalized contact on the part of the facilitators. Some respondents mentioned telephone interaction as an option within their programs, which may be a solution for those students who truly need more one-on-one, personalized contact. Online education instructors may be inspired to try to improve their teaching strategy by identifying individual contributions to group projects and promoting cooperation between peers. This study and its implications can extend beyond the specific topic of RN-BSN education and could relate to other fields with characteristics like online nursing education.

This study is limited in several ways because of the nature of the study. One limitation lies in the researcher having been unable to conduct face-to-face interviews because participants were selected by network or snowball sampling. Study participants were in various states across the country, necessitating telephone conferences to complete the interview process. Nonverbal cues (e.g., facial expressions, hand gestures, body position) could not be captured or interpreted. All interviews were audiorecorded with the participants' permission. As in any qualitative study that relies on interview data, the environment and personal characteristics could affect the participants' responses; this study was not able to capture and evaluate this important information. These limitations may restrict the application of insights regarding the distance education experiences reported by the study participants to all RN-BSN students.

During her own practice, the researcher has had experiences with diploma, ADN-, and BSN-prepared nurses. These experiences have shaped the researcher's own feelings and opinions regarding entry into practice. The findings of the study could be biased because of the researcher's influence on the interpretation on the interviews.

This qualitative interview study identified the perceptions and experiences of nursing students regarding online nursing education in RN-BSN programs. The study explored the preprogram assumptions and post-program experienced perceptions of these students. Based on the analysis of data, six themes emerged involving the perceptions and experiences nursing students have regarding distance nursing education.

This study yielded valuable insights into the perceptions and experiences nursing students had regarding online education program. Results of this study demonstrate overwhelming approval of these types of programs within the study sample, with a stated $100 \%$ satisfaction among participants. The most frequently stated advantage of an online learning environment is flexibility; the major disadvantages mentioned by participants in this study included the lack of face-to-face or in-person contact and 
weakness of the process of group projects in the programs. These findings have important implications for theory, as well as future research and practice.

Findings from this qualitative research can be used to expand the body of knowledge about online nursing education and be compared with findings from past research on distance education in other fields. The findings from this study may assist online education instructors and administrators in understanding and making decisions about their distance education programs and course design. The study may also be beneficial for developing strategies to improve the perceptions and learning experiences of nursing students reported about the online education program.

Further research into this topic may contribute to the body of knowledge that might assist instructors and administers in nursing education to ascertain and mitigate the barriers and disadvantages of online education programs while maintaining and expanding its advantages. This objective might be achieved by conducting an anonymous survey, which could be administered to sample from a large population of nursing students regarding distance education.

Addition research might also be conducted on whether the educators and administrators are cognizant of the experiences and perceptions of nursing students have regarding distance education and what kinds of strategies have been developed to resolve the issues raised in this study. Further qualitative studies should be performed with larger sample populations so that their results can be compared to the findings of this study. Differences in perceptions and experiences from nursing students regarding distance education may be derived from such studies.

\section{References}

America Association of College of Nursing (AACN). (2015). The Impact of Education on Nursing Practice. Retrieved from http://www.aacn.nche.edu/media-relations/fact-sheets/impact-of-education

American Association of Colleges of Nursing (AACN). (2008). The essentials of baccalaureate education for professional nursing practice. Retrieved from http://www.aacn.nche.edu/Education/pdf/BaccEssentials08.pdf

American Association of Colleges of Nursing (AACN). (2011). 2010-2011 Enrollment and graduations in baccalaureate and graduate programs in nursing. Washington, DC: Author.

American Association of Colleges of Nursing (AACN). (2017). Degree Completion Programs for Registered Nurses: RN to Master's Degree and RN to Baccalaureate Programs. Retrieved from http://www.aacn.nche.edu/media-relations/fact-sheets/degree-completion-programs

American Organization of Nurse Executives (AONE). (2005). AONE Practice and education partnership for the future. Retrieved June 10, 2007, from http://www.aone.org/aone/resource/practiceandeducation.html

American Organization of Nurse Executives (AONE). (2015). Advancing Academic Progression in Nursing Education: An Emerging Model is Identified and Refined. Retrieved from 
http://www.aone.org/docs/apin/apin-voice-may-2015.pdf

Colaizzi, P. F. (1978). Psychological research as the phenomenologist views it. In R. S. Valle, \& M. King (Eds.), Existential-phenomenological alternatives for psychology (pp. 48-71). New York: Oxford University Press.

Council on Physician and Nursing Supply. (2007). New council calls for immediate increase in physician and nurse education [Press release]. Retrieved from http://www.physiciannursesupply.com/Articles/council-meeting-release.pdf

Health Resources and Services Administration. (2010, September). The Registered Nurse Population: Findings From the 2008 National Sample Survey of Registered Nurses. Washington, DC: USA Department of Health and Human Services.

Institute of Medicine. (2010). The Future of Nursing: Leading Change, Advancing Health. Washington, DC: National Academies Press.

National Advisory Council on Nursing Education and Practice. (2003). Third report to the Secretary of the Department of Health and Human Services and the Congress. Washington, DC: USA Department of Health and Human Services, Health Resources and Service Administration, Bureau of Health Professions, Division of Nursing.

Sit, J. W., Chung, J. W., Chow, M. C., \& Wong, T. K. (2005). Experiences of online learning: Students' perspective. Nurse Education Today, 25, 140-147. https://doi.org/10.1016/j.nedt.2004.11.004

\section{Appendix A}

\section{Interview Questions}

a) "Can you describe your learning experience in the RN-BSN distance education program?"

b) "When you entered the program, what were your perceptions/assumptions about the learning experience in a distance education program?"

c) "How do those perceptions/assumptions compare with your actual learning experiences?"

d) "What advantages do you think distance education programs offer?"

e) "What disadvantages do you think there are in this type of learning environment?"

f) "How do you think your educational experiences compare with those of traditional RN-BSN programs?"

g) "Do you feel the learning experiences in the program are relevant to your practice?"

h) "How satisfied are you with the overall distance learning experience?" 